\title{
PULSE THERMOGRAPHY FOR QUALITY AND RELIABILITY EVALUATION OF ADVANCED MATERIAL
}

\author{
Soo-Yong Choi ${ }^{1+}$, Min-Jung Park ${ }^{1}$, Ki-Tae Yoo ${ }^{1}$, Jae-Yeon Kim ${ }^{1}$, Jai-Won Byeon ${ }^{1 *}$ \\ ${ }^{1}$ Seoul National University of Science and Technology, Seoul, Korea \\ ${ }^{\dagger}$ Presenting Author: sychoi13@ seoultech.ac.rk \\ *Corresponding Author: byeonjw@ seoultech.ac.kr
}

\begin{abstract}
In this laboratory, a pulse thermography technique has been developed for nondestructive quality evaluation of advanced thin materials including battery electrode examination, thin film ceramic heater, porous/bulk titanium bonding composite, and thin metallic sheet. For rapid detection of fine defects, short pulse type optical excitation was made by applying a 6KJ Zenon lamp. Detects were tried to be quantified by correlating thermal contrast maximum with defect characteristics (i,e., type, depth, material). As a typical application, quality factor of lithium ion battery electrodes such as weak interfacial bonding between active ceramic material and thin metallic substrate was successfully examined. Harmful chemical deposit, which is not easily observed by optical examination, was also detected on the electrode surface. Secondly, feasibility of detecting subsuface damage (i.e., pin hole generated on the glass substrate during ceramic thin film deposition process) was shown. Thirdly, for quality evaluation of surface-porous titanium implant, interfacial bonding defect between bulk and porous sheet was examined. Based on the successful results, feasibilities of pulse thermography with high power optical excitation for quality examination of advanced components were discussed.
\end{abstract}

KEYWORDS: pulse thermography, quality evaluation, advanced thin material

\section{EXPERIMENTAL}

\subsection{PULSE THERMOGRAPHY TECHNIQU}

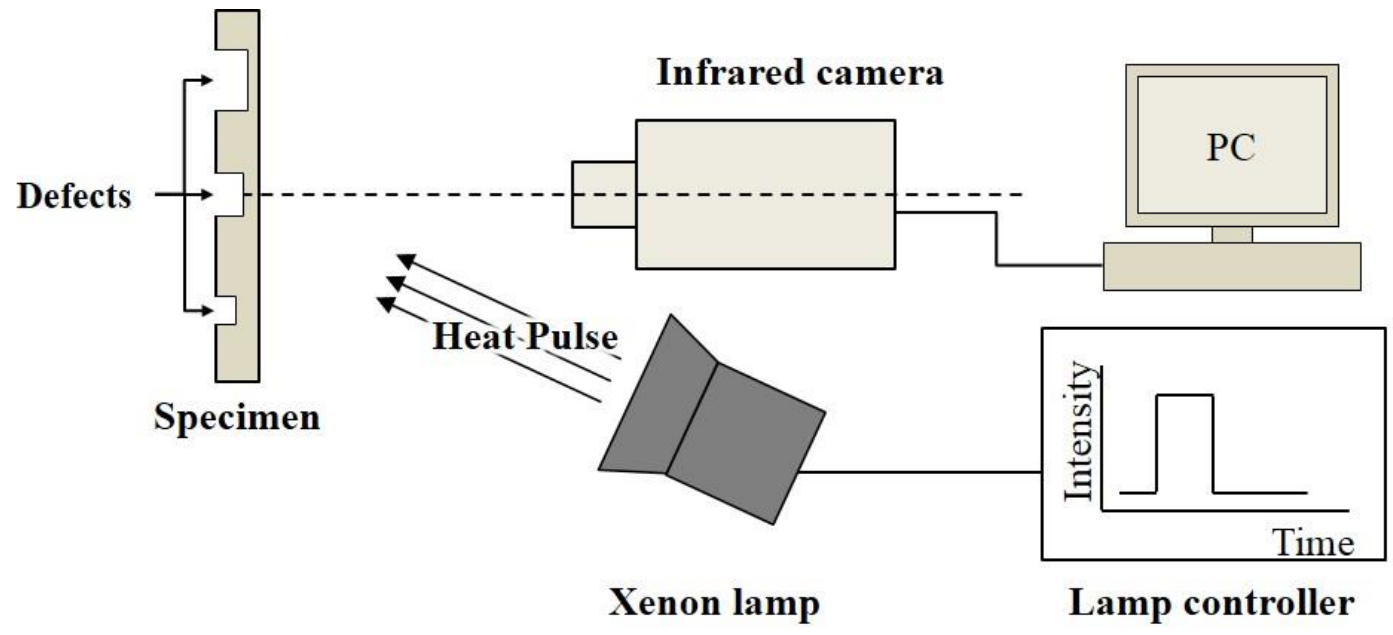

Fig. 1 Schematic of the pulse thermography technique. 


\section{RESULTS}

\subsection{BETTERY ELECTRODE}

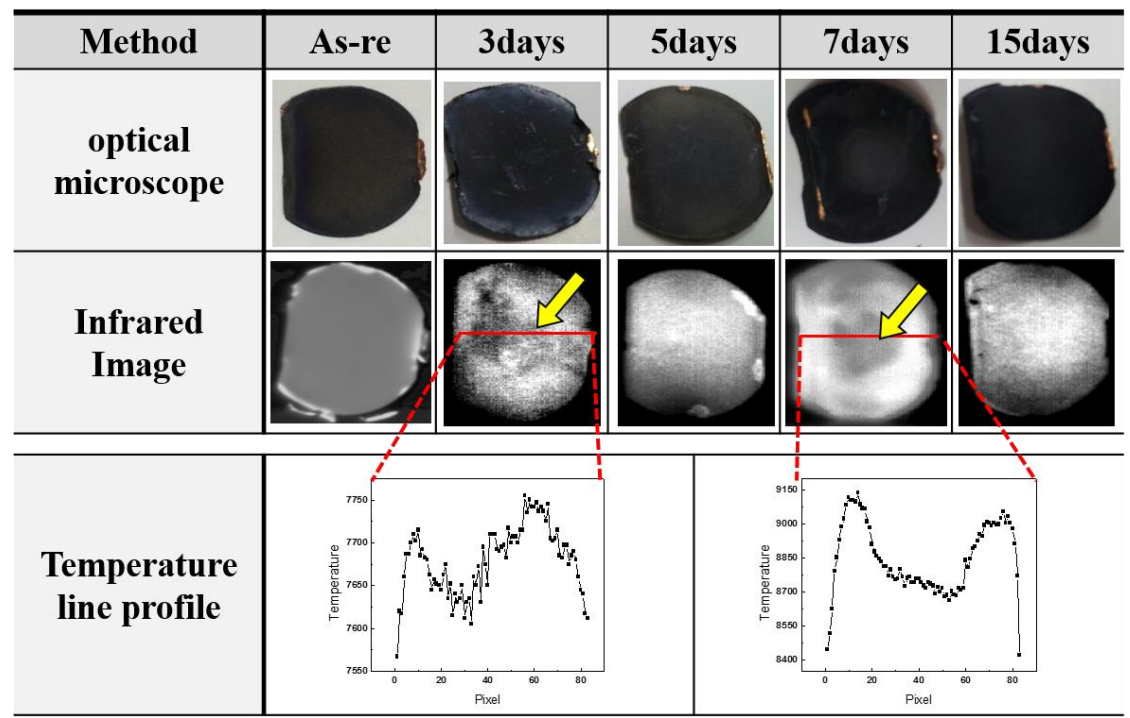

Fig. 2 Thermography of battery anode electrodes according to the time exposed to high temperature.

\subsection{THIN FILM CERAMIC HEATER}

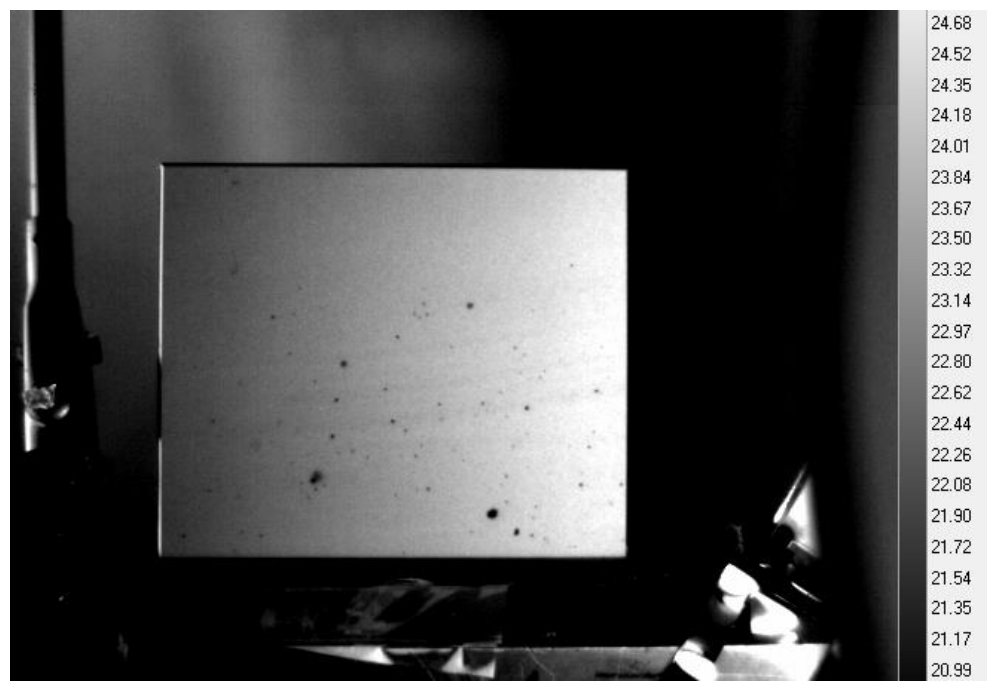

Fig. 3 Thermography of FTO thin film with the defect due to impurities. 


\subsection{POROUS/BULK TITANIUM BONDING COMPOSIT}

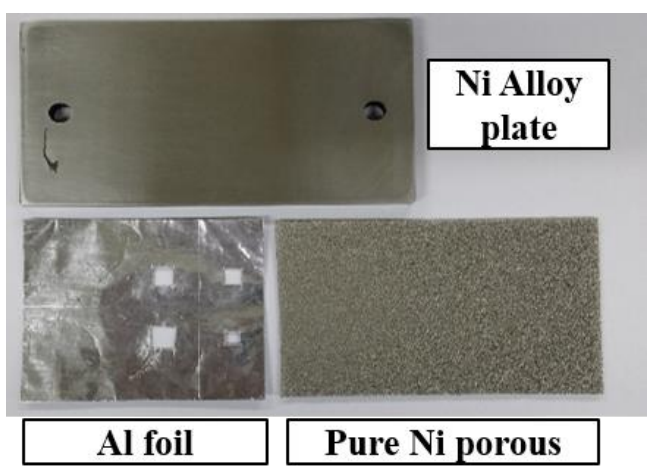

Fig. 4 Components of the porous/bulk titanium bonding composite with artificial defects made by perforated filler metal.

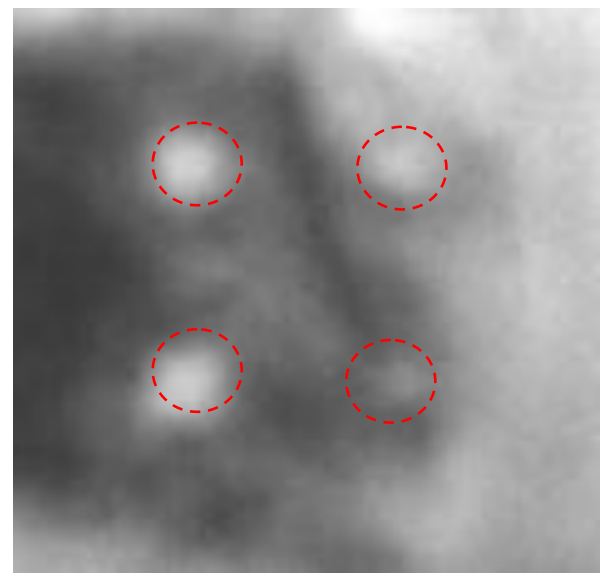

Fig. 5 Thermography of the porous/bulk titanium bonding composite.

\subsection{THIN METAL SHEET}

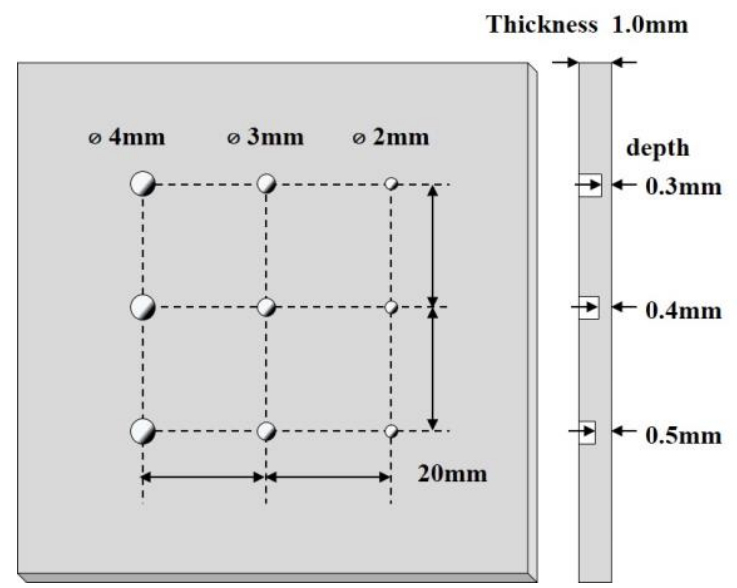

Fig. 6 Schematic of the steel sheet designed with artificial defects. 
http://dx.doi.org/10.21611/qirt.2017.055

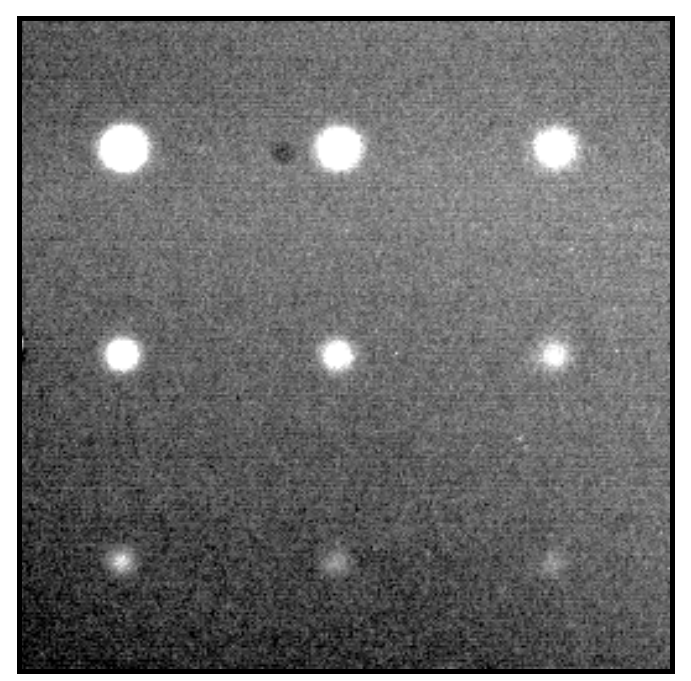

Fig. 7 Thermography of the steel sheet with artificial defects. 